\title{
Extracorporeal Treatment for the Acute und Long-Term Outcome of Patients with Life-Threatening Acquired Hemophilia
}

\author{
Heike Zeitler ${ }^{\mathrm{a}}$ Gudrun Ulrich-Merzenich ${ }^{\mathrm{a}}$ Darius Panek ${ }^{\mathrm{a}}$ Georg Goldmann ${ }^{\mathrm{b}}$ \\ Natascha Vidovic $^{b}$ Hans-Hermann Brackmann ${ }^{b}$ Johannes Oldenburg ${ }^{b}$ \\ anternal Medical Clinic I, Center of Extracorporeal Therapy and Autoimmunity (CETA), \\ bInstitute of Experimental Hematology and Transfusion Medicine, University of Bonn, Germany
}

\section{Keywords}

Acquired Hemophilia - FVIII - Immune tolerance induction . MBMP · Immunomodulation · Immunoadsorption · APTT

\section{Summary}

Objectives: In acquired hemophilia $(\mathrm{AH})$, autoantibodies (inhibitors) impede blood coagulation factors leading to severe bleedings. Cornerstones of a successful treatment are the control of bleeding and an eradication of autoantibodies. The present study is an update of our previous documentation of the treatment of high-titer $\mathrm{AH}$ patients with severe life-threatening bleeding undergoing the modified Bonn-Malmö-Protocol (MBMP). Methods: $64 \mathrm{AH}$ patients were treated by a standard combination protocol (MBMP) consisting of antibody depletion through immunoadsorption, i.v. immunoglobulin, immunosuppression, and high-dose FVIII substitution. They underwent a long-term follow-up. Results: Primary study endpoints loss of detection of the activity of the inhibitor and FVIII recovery $\geq 5 \%$ were reached in a median time of 3 days (95\% $\mathrm{Cl}: 2.6-3.4$ days), the median time of FVIII substitution was 13 days $(95 \% \mathrm{Cl} 10.6-15.3$ days), and the median time of immunoadsorption was 16 days $(95 \% \mathrm{Cl} 13-18.9$ days). In 5 patients the $\mathrm{AH}$ occurred as paraneoplastic syndrome, and partial remission was achieved. Relapses without bleeding event occurred only in second-line MBMP. Those responded excellently to short time treatment. Overall patients remained in remission over a median follow-up time of 8 years. Conclusion: Except for paraneoplastic AH, MBMPtreated patients have a remarkable prognosis which is confirmed by long-term follow-up with a complete response rate of $93 \%(53 / 57)$ in the first year post MBMP and $100 \%$ during long-term follow-up. These outcome in life-threatening $\mathrm{AH}$ is unique and until now not achievable via other treatment schedules. In life-threatening bleedings physicians should take into account MBMP as a first line treatment.

\section{Schlüsselwörter}

Erworbene Hämophilie · FVIII · Immuntoleranzinduktion . MBMP · Immunmodulation · Immunadsorption · APTT

\section{Zusammenfassung}

Hintergrund: Autoantikörper (Inhibitoren) gegen Gerinnungsfaktoren sind die Ursache der erworbenen Hämophilie, die klinisch durch schwere Weichteilhämatome charakterisiert ist. Blutungskontrolle und Inhibitoreradikation sind die wesentlichen Bestandteile einer erfolgreichen Hemmkörpertherapie. Diese Studie ist ein Update der zurvor in 2005 veröffentlichen Daten von hochtitrigen Hemmkörperpatienten mit lebensbedrohlichen Blutungen, die mit dem modifizierten BonnMalmö-Protokoll (MBMP) therapiert wurden. Methoden: 64 Patienten wurden mit einem standardisierten Protokoll bestehend aus Antikörperdepletion mittels Immunoadsorption, i.v Immunglobulingabe, Immunsuppression und hochdosierter FVIII-Gabe therapiert. Alle Patienten wurden im Langzeit-Follow-up nachbeobachtet. Ergebnisse: Die primären Endpunkte, wie nicht mehr detektierbarer Inhibitor einhergehend mit einer FVIII-Recovery $\geq 5 \%$, wurden im Median nach 3 Tagen (95\% Cl 2,6-3,4 Tage) erreicht, die mediane Zeit der Faktorsubstitution lag bei 13 Tagen ( $95 \% \mathrm{Cl} 10,6-15,3$ Tage), und die mediane Zeit der Apherese betrug 16 Tage (95\% Cl 13-18,9 Tage). Fünf Patienten mit einem paraneoplastische Syndrom erreichten eine partielle Remission. Rückfälle ohne erneutes Blutungsereignis traten nur auf bei Patienten, die second-line mit dem MBMP behandelt wurden. Sie sprachen auf eine erneute kurzzeitige Therapie prompt an. Die übrigen Patienten erreichten eine komplette Remission die in einem LangzeitFollow-up von im Median 8 Jahren verifiziert werden konnte. Schlussfolgerung: Nach Ausschluss von Patienten mit einem paraneoplastischen Syndrom erreicht das MBMP bei Patienten mit erworbener Hämophilie eine Remissionsrate von $93 \%$ (53/57) im ersten Jahr nach MBMB und eine von 100\% im Langzeit-Follow-up. Diese Langzeitergebnisse bei lebensbedrohlicher erworbener Hämophilie können aktuell mit keiner anderen Behandlungsmethode erreicht werden. Diesbezüglich sollte bei lebensbedrohlichen Blutungen das MBMP als First-line-Therapie in Betracht gezogen werden.

\section{KARGER \\ Fax +497614520714 \\ Information@Karger.de}

www.karger.com
(C) 2012 S. Karger GmbH, Freiburg

660-3796/12/0394-0264\$38.00/0

Accessible online at:

www.karger.com/tm
Dr. med. Zeitler Heike

Internal Medical Clinic I, CETA

University of Bonn

Sigmund-Freud-Straße 27, 53127 Bonn, Germany

Tel. +49 228287 136-28, Fax -30

heike.zeitler@ukb.uni-bonn.de 


\section{Introduction}

Severe soft tissue and muscles hematomas are, in contrast to hemarthrosis in congenital hemophilia, the hallmark of acquired hemophilia (AH). An autoantibody (inhibitor) directed against a coagulation factor inhibits either the activity or increases the clearance rate. Commonly inhibitors are directed against clotting factor FVIII and rather seldom against FIX [1]. Recently Lacroix-Desmazes et al. [2] detected the presence of an $\mathrm{IgG}$ inhibitor with proteolytic activity in vivo and in vitro. The prolongation of the activated partial thromboplastin time (aPPT) is the most important diagnostic criterium to suspect an $\mathrm{AH}$. Diagnosis must be confirmed by a clotting factor analysis, followed by the verification of the presence of the inhibitor via the Bethesda assay [3].

With an overall incidence of 1-4 per million/year AH belongs to the group of rare disorders [4], but as mentioned by several authors, it might be underdiagnosed due to its scarcity [4-6]. In up to $18 \%$ of patients with $\mathrm{AH}$ other autoimmune disorders are detected [7], but also the postpartum period and chirurgical interventions are critical for inhibitor induction [8]. Solid organ tumors and hematological malignancies, especially in elderly patients, are also regarded as causes of $\mathrm{AH}$ [9]. Aouba et al. [10] divided therefore $\mathrm{AH}$ in an 'idiopathic form' and an 'acquired hemophilia with specific associated conditions' (AHSAC). The former group is reported to have a 2.5-fold higher mortality rate. Several studies and a metaanalysis had shown that patient's prognosis mainly depends on the immediate bleeding control and fast inhibitor eradication [10].

Bypassing factors like activated prothrombin complex concentrate (aPCC) $\left(\right.$ FEIBA $^{\circledR}$, Baxter, Deerfield, IL, USA) and recombinant FVIIa (rFVIIa) (Novoseven ${ }^{\circledR}$; Novo Nordisk, Princeton, NJ, USA) were shown to control bleedings equally sufficient with response rates of $80-91 \%$ [4]. In severe bleedings a median of 10 infusions achieve a hemostatic control in up to $76 \%$ [4], with a median time to respond of 5 days (range 2-10 days), as shown by the EACH2 data [7]. The data of the EACH2 Registry recently published by Baudo et al. [11] have shown that bleeding control was significantly better with bypassing factors versus FVIII/DDAVP (93.3 vs. 68.3\%). Bleeding control was similar when comparing rFVIIa and aPCC (93\%; $p=1)$ Limitations of this coagulation treatment might be their dose-dependent risk for thromboembolism and cardiovascular events especially in elderly patient collectives [12]. Recently published data of Ingerslev et al. [13] and Katgri et al. [14] had shown that bypassing factors, alone or in combination, have an excellent efficacy to control bleedings, but in 5 of $9 \mathrm{AH}$ patients thrombotic complications occurred. In the Düsseldorf Interim analysis, one death of a patient from acute myocardial infarction during the first 30 days of treatment was reported while being on antihemorrhagic treatment with high-dose rFVIIa [6], a second patient died of acute sepsis during the immunosuppressive treatment also during the first 30 days [6]. The EACH2 Registry had shown thrombotic events in $3.6 \%$ of treated patients with a similar incidence in rFVIIa (2.9\%) and aPCC (4.8\%) [11].

Thus besides control the bleeding, a successful inhibitor elimination strategy should be initiated as soon as the diagnosis is confirmed. The most established immunosuppressive treatment consists of steroid alone or in combination with cyclophosphamide. The reported complete remission rates of $50-76 \%$ [4] for this choice of treatment can, however, be questioned, since high relapse rates of about $20 \%$ are reported already after a median of 7.5 months of follow-up (1 week to 14 months). Finally, no data about the long-term outcome and prognosis of 'relapsing $\mathrm{AH}$ ' after failing to respond to a conventional treatment are available, a fact that should be considered when interpreting the data and outcomes in these treatment schedules.

Despite of these intensive treatment regimens, the estimated overall lethality still ranges in different publications from 9 to $76 \%$ [4, 12, 15]. Giraud et al. [16] and Lambotte et al. [17] described higher rates of mortality in series of older patients: $31 \%(18 / 58)$ and $76 \%(17 / 22)$, respectively. These higher rates mainly depend on patient's risk factors like inhibitor titer, severity of bleeding, and comorbidities. A recently published 'multiple cause analysis for best care strategies analyzed deaths in AH from 2000-2009 [10] and noted that hemorrhagic shock was the most frequent direct cause of death $(52.9 \%)$ followed by infections $(26.4 \%)$ due to longterm immunosuppressive treatment.

Therefore an optimal treatment strategy in AH should include, in addition to the immediate control of bleedings, the fast re-induction of immune tolerance versus FVIII.

Immunoadsorption is one cornerstone of an intensive short-time treatment schedule performed at our center. Its combination with an immunosuppressive treatment results in the inhibition of the inhibitor de novo synthesis. Further, the FVIII substitution allows a successful and fast re-establishment of a stabile hemostasis

The present study is an update of our previous documentations of the treatment of high-titer $\mathrm{AH}$ patients with severe life-threatening bleeding undergoing the modified BonnMalmö-Protocol (MBMP) with an emphasis on the role of immunoabsorption for the outcome of the treatment [18-20].

\section{Patients and Methods}

\section{Patients}

Between 1993 and 2012, a series of 64 patients, suffering from life-threatening AH were treated with the MBMP. All patients had high inhibitor titer levels to FVIII ( $>5 \mathrm{BU}$ ) [3] and the incidence of at least one acute bleeding episode (drop of hemoglobin to $<8.0 \mathrm{mg} / \mathrm{dl}$ ). The Ethics Committee of the Medical Faculty at the University of Bonn approved the treatment protocol. All patients or their responsible relatives gave their informed consent in writing.

The inhibitor analysis was performed with the Bethesda assay modified by Nijmegen [3]. Differential diagnosis with respect to the lupus ery- 


\section{i.v. $\lg$}

Immunoadsorption

Immunosuppression

FVIII administration

\section{rFVIIa}

12

3

4

5

6

7

Day

Fig. 1. The MBMP treatment cycle.

thematosus-associated inhibitor was established with the dilute Russell viper venom test, the lupus-activated partial thromboplastin time, the plasma dilution test, and the determinations of FII, FV, FVII, FIX, FX, and FXI. The FVIII levels were determined by two methods: the onestage clotting assay and the chromogenic FVIII assay. rFVIIa was substituted in 62 patients after diagnosis to achieve an immediate reduction in bleeding diathesis during the patient's transfer to our hospital.

Complete remission was defined as normal FVIII activity (70-140\%) without factor substitution and undetectable inhibitor titer levels during a minimum follow-up period of 12 months.

Partial remission was defined as attaining FVIII recoveries by up to $30 \%$ and/or a reduction of the inhibitor titer to less than $5 \mathrm{BU}$ without further bleeding events.

A total of 64 patients with $\mathrm{AH}$ were treated as follows:

i) Large-volume immunoadsorption $(2.5-3 \times$ total plasma volume on days $1-5)$.

ii) IVIG substitution ( $0.3 \mathrm{~g} / \mathrm{kg}$ body weight (BW)/day, on days $5-7)$.

iii) Immunosuppressive therapy with cyclophosphamide (1-2 mg/kg BW/ day) and prednisolone ( $1 \mathrm{mg} / \mathrm{kg} \mathrm{BW} /$ day $)$ from day 1 until remission (dose reduction).

iv) Administration of FVIII (100 U/kg BW and, in exceptional cases (BMI $>40 \mathrm{~kg} / \mathrm{m}^{2}$ ), up to $200 \mathrm{U} / \mathrm{kg} \mathrm{BW}$ ) every $6 \mathrm{~h}$. Optional dose reduction on the basis of clinical signs and the level of recovery achieved (50-80\% FVIII residual activity after 4-6 h) throughout the treatment cycle.

The treatment cycles (from day 1 to day 7) were repeated, depending on the clinical response and coagulation factor activity. The treatment schedule is visualized in figure 1.

Immunoadsorption was accomplished by apheresis of sheep-derived polyvalent antihuman Ig bound to sepharose CL 4B (Amersham Pharmacia, Biotech AB, Uppsala, Sweden), using a dual-column system (Ig Therasorb Miltenyi Biotec GmbH, Bergisch Gladbach, Germany). Blood was drawn from an antecubital vein on one arm at a rate of up to 70 $\mathrm{ml} / \mathrm{min}$ and returned after processing via an antecubital vein on the other arm. Alternatively, in the case of inadequate antecubital vein access, a biluminal central venous catheter was placed. Plasma was continuously separated at a flow rate of up to $80 \mathrm{ml} / \mathrm{min}$ using either of three apheresis systems (Cobe Spectra, Caridian Terumo BCT, Adasorb Medicap) or one-in-two technology of LIFE 18 (Miltenyi Biotec) with acid-citratedextrose (ACD-A, Baxter Healthcare Corp., Round Lake, IL, USA) as an anticoagulant diluted 1:30 or 1:40, respectively, in the two systems. The separated plasma was passed through the columns. The adsorptive capacity of the columns was $1.25 \mathrm{~g}$ for all IgG subclasses. [18-20]. The target of processing was 2.5 times the plasma volume, and apheresis was continued for 5 days in each treatment cycle.

\section{Data Analysis}

All statistical analyses were performed using the Statistical Package for Social Sciences IBM SPSS, version 19.0 (SPSS, Inc., Chicago, IL, USA). Nonparametric statistics and Pearson's rank correlation $\left(\mathrm{r}_{\mathrm{s}}\right)$ test were used.

The primary study endpoints were the time at which i) activity of the inhibitor was first undetectable allowing a FVIII recovery of up to $\geq 5 \%$, ii) the factor substitution could be discontinued and iii) MBMP treatment was terminated without the requirement for further apheresis. KaplanMeier analysis was performed to evaluate the time at which these endpoints were reached. The median time to reach these endpoints was calculated on the basis of the associated $95 \%$ confidence intervals (95\% CI).

\section{Results}

Patients Characteristics, Laboratory and Clinical Parameters A total of 64 patients (26 male, 38 female) of AH with hightiter inhibitor levels ( $>5 \mathrm{BU}$ ) were diagnosed in our hospital. All patients exhibited life-threatening bleeding (maximum hemoglobin on admission $8.0 \mathrm{~g} / \mathrm{dl}$ ) requiring blood transfusions, factor concentrate substitution, and intensive care monitoring. The mean hemoglobin concentration on admission in our hospital was $6.9 \mathrm{~g} / \mathrm{dl}$ (range 3.1-8.2 g/d). All patients suffered from severe multifocal bleedings. The types of bleeding observed included muscle bleeding events $(n=65)$ associated with compartment syndrome $(\mathrm{n}=8)$, gastrointestinal bleeding $(\mathrm{n}=3)$, retroperitoneal bleeding $(\mathrm{n}=18)$, retropharyngeal bleeding, which required artificial respiration $(\mathrm{n}=5)$, and hematuria $(\mathrm{n}=4)$.

The mean age of the patients was 65.61 years (range 28-89 years). Excluding patients developing the inhibitor post partum, the mean age was 69.01 years (range 49-89 years).

The mean FVIII level at initial diagnosis and at the beginning of the MBMP was $<1 \%$ (normal $70-140 \%$ ). The mean inhibitor titer was $238 \mathrm{BU} / \mathrm{ml}$ (range $8-3,600 \mathrm{BU} / \mathrm{ml}$ ). The mean aPTT on admission was $58.27 \pm 22.86 \mathrm{~s}$.

Underlying diseases were detected in 12 patients. In 6 women, the inhibitor was diagnosed peripartially (i.e. within 3 months of childbirth). Eight patients suffered from other autoimmune diseases (mixed connective tissue disease $n=6$, psoriasis $n=4$, polymyalgia rheumatica $n=1$, Sjögren syndrome $\mathrm{n}=1$ ), and in 5 patients the inhibitor occurred as paraneoplastic syndrome (lung cancer $\mathrm{n}=1$, plasmocytoma $\mathrm{n}=2$, lymphoma $\mathrm{n}=1$, breast cancer $\mathrm{n}=1$ ).

In 5 patients the immunosuppressive treatment was initiated in a peripheral hospital. Steroids and cyclophosphamide were given to all patients, whereas other treatments (vincristin $\mathrm{n}=2$, azathioprine $\mathrm{n}=4$, rituximab $\mathrm{n}=2$ ) were given only to individual patients. In all patients bleedings continued. Therefore, they were switched over to MBMP, and the immunosuppressive treatment was changed to steroids and cyclophosphamide as mentioned above. Vincristine, azathioprine, and rituximab were discontinued.

A total of 1,202 immunoadsorption procedures (apheresis) were carried out. The extracorporeal treatment was well tol- 

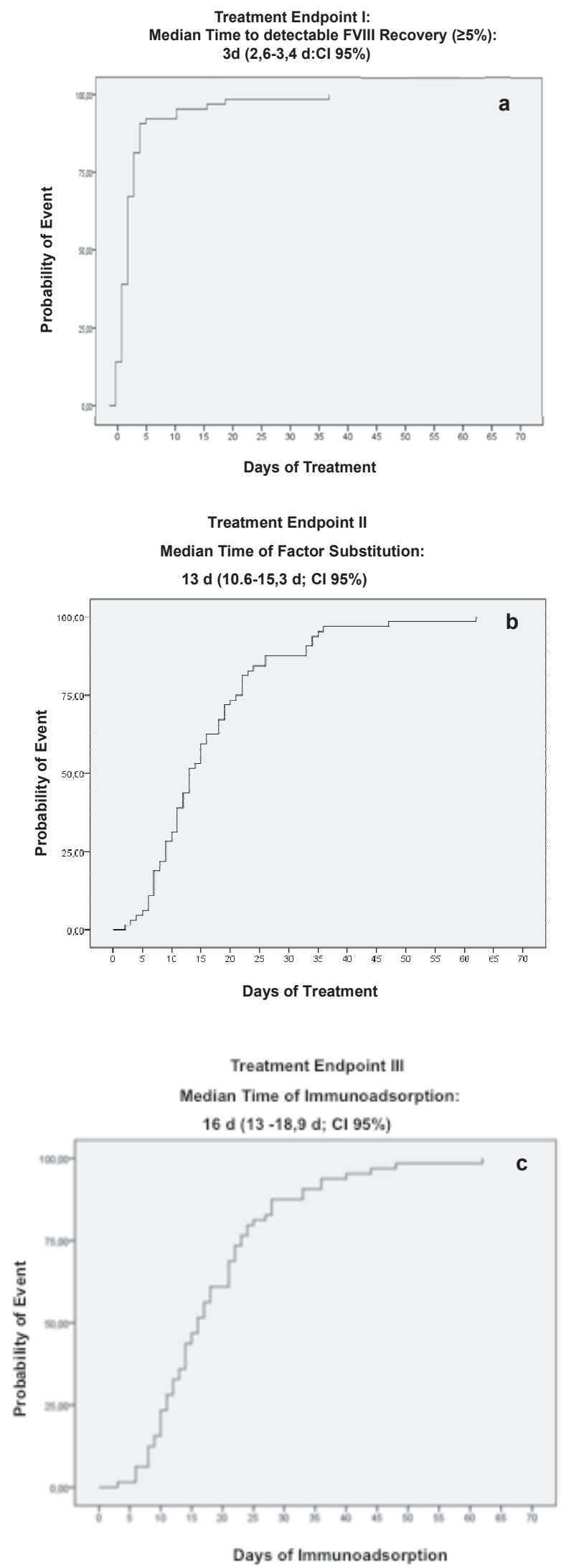

Fig. 2. Treatment endpoints were rapidly reached in the MBMP group. Kaplan-Meier plots of a median time to detectable FVIII recovery ( $\geq 5 \%$ ): 3 days ( $95 \%$ CI 2.6-3.4 days) b median time of factor substitution: 13 days ( $95 \%$ CI 10.6-15.3 days), and $\mathbf{c}$ median time of immunoadsorption: 16 days (95\% CI 13-18.9 days).

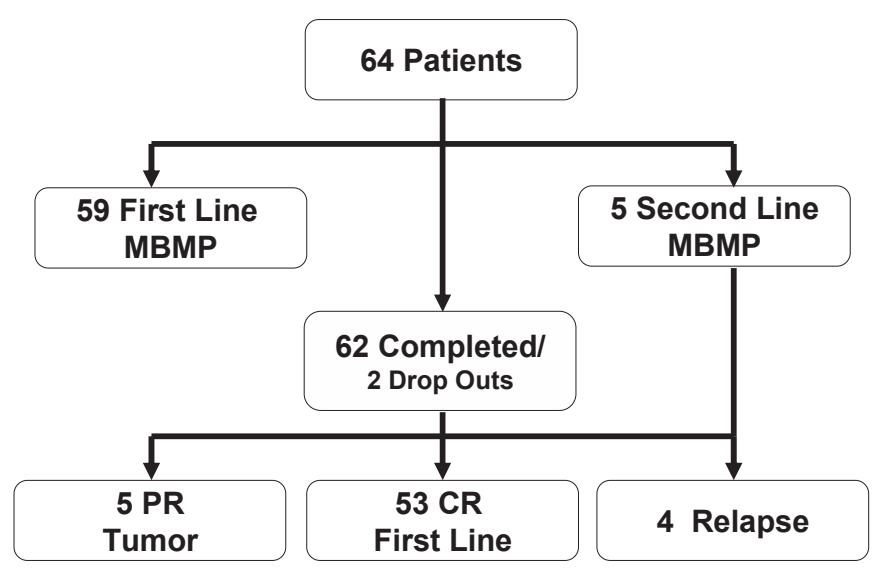

Fig. 3. Overview (number of patients undergoing first line or second line the MBMP, and patients' outcome). Schematic summary of the number of enrolled patients receiving MBMP, conventional treatment or both, and their clinical outcome.

erated. Mild side effects such as hypotension, hypesthesia due to citrate anticoagulation (citric reactions), and allergic reactions occurred in less than $1 \%$ of all apheresis sessions. None did require an interruption of treatment. A median plasma volume of $6,050 \mathrm{ml}$ (range 3,700-9,500 $\mathrm{ml}$ ) was used.

\section{Treatment Endpoints and Clinically Relevant Correlations}

The primary study endpoint loss of detection of the activity of the inhibitor and FVIII recovery $\geq 5 \%$ were reached in a median time of 3 days (95\% CI 2.6-3.4 days) (fig. 2a), the median time of FVIII substitution was 13 days (95\% CI 10.6-15.3 days) (fig. 2b), and the median time of immunoadsorption was 16 days ( $95 \%$ CI $13-18.9$ days) (fig. 2 c).

The median FVIII consumption was $0.185 \times 10^{6} \mathrm{IE}$ (range $\left.0.024-1.9 \times 10^{6} \mathrm{IE}\right)$.

The median rFVIIa consumption was $0.738 \times 10^{3} \mathrm{IE}$ (range $\left.0-0.824 \times 10^{3} \mathrm{IE}\right)$.

There was a significant correlation between the inhibitor titer and FVIII/rFVIIa consumption $\left(r_{\mathrm{s}}=0.594, \mathrm{r}_{\mathrm{s}}=0.369\right.$, $\mathrm{p}=0.01)$, endpoint I $\left(\mathrm{r}_{\mathrm{s}}=0.646, \mathrm{p}=0.01\right)$ endpoint II $\left(\mathrm{r}_{\mathrm{s}}=\right.$ $0.580, \mathrm{p}=0.01)$, endpoint III $\left(\mathrm{r}_{\mathrm{s}}=0.569, \mathrm{p}=0.01\right)$ and days of hospitalization $\left(\mathrm{r}_{\mathrm{s}}=0.521, \mathrm{p}=0.01\right)$.

\section{Clinical Outcome, Treatment Efficacy, and Side Effects}

Once the immunoadsorption was initiated, the bleeding was controlled within the first 2 apheresis sessions.

There was no bleeding-associated mortality in the MBMP group.

From 64 patients who underwent the MBMP, 62 patients completed the MBMP (fig. 3) successfully. In 2 patients, the MBMP was interrupted as consequence of other concomitant diseases. At the time of interruption partial remission had been achieved in both patients; one patient converted 2 months after MBMP spontaneously to CR, the other died within 3 months due to an epileptic seizure that was not related to $\mathrm{AH}$. 
In 5 patients, cancer was diagnosed during MBMP. These patients achieved a partial remission (small cell lung cancer $\mathrm{n}=1$, plasmocytoma $\mathrm{n}=2$, lymphoma $\mathrm{n}=1$, breast cancer $\mathrm{n}=1$ ). A FVIII recovery $>30 \%$ after MBMP allowed safe tumor staging procedures (mediastinocopy $\mathrm{n}=1$, mastectomy $\mathrm{n}=1$, bone marrow aspiration $\mathrm{n}=4$; pleural punction, pleurodesis $\mathrm{n}=3$ ) without any bleeding or infection complications.

During long-term follow-up, 4 patients experienced a period of FVIII decline to $10-50 \%$, without any bleeding events 8, 9 and 12 months after the completions of the MBMP (fig. 3). These patients were treated first line with a conventional immunosuppressive treatment as reported above and then switched to MBMP. Two of them responded well to a short-time apheresis of 5-6 days in combination with immunosuppressive treatment for another 3 weeks. One patient was treated only with a short-time cycle of steroids for 3 weeks. The 4 th patient had received a pretreatment of rituximab, and the relapse was treated successfully with further 4 cycles of rituximab $375 \mathrm{mg} / \mathrm{m}^{2}$ body surface area and a low dose of steroid. These interventions were successful in restoring normal FVIII levels, and hemostasis remained stable without further relapses. During a longterm follow-up of a mean 98.2 months (range 12-168 months), there was no evidence of any further inhibitor relapse.

During long-term follow-up all patients suffering from malignancy died in consequence of tumor disease. The inhibitor occurred simultaneously to the tumor disease. Although MBMP achieved a partial remission with a sufficient FVIII $>30 \%$, tumor-adapted chemotherapy improved the coagulation situation further. Inhibitor-associated complication did not occur again, not even in end stage tumor progress.

Finally, when the 5 patients with paraneoplastic syndrome were excluded, 53 of 57 patients achieved a complete remission $(93 \%)$.

Relapses were seen in the first year after completing MBMP and occurred only in patients treated second line by MBMP. During long-term follow-up later than 1 year after completing MBMP, none of the patients relapsed (remission rate of $100 \%$ ).

Apheresis-related adverse events, which led to treatment interruption, did not occur.

Severe adverse events due to the immunosuppressive treatment occurred in 6, catheter-associated sepsis in 4, and pneumonia in 2 patients; cyclophosphamide-induced cystitis was seen in 1 patient. A treatment interruption was necessary in 1 patient due to neutropenia. All other infections were successfully treated by conventional antibiotics. Daily blood counts and CRP levels for an intense infection screening were performed in all patients. Cyclophosphamide was dose-adapted to renal function and blood cell count.

\section{Discussion}

Patients suffering from $\mathrm{AH}$ are at high risk of fatal bleedings any time until the inhibitor has been eradicated. Complications such as hemorrhagic shock and infection are the main direct causes of death in $\mathrm{AH}$ [10]. Relevant prognostic factors for the treatment response in $\mathrm{AH}$ have been analyzed by the meta-analysis of Delgado et al. in 2003 [12]. Based on data of 249 patients, the authors showed that after 6 weeks of immunosuppressive treatment the rate of adverse events increased to $53 \%$; of those $15 \%$ died due to infection. These data were confirmed in 2007 by the SACHA study. The standard immunosuppressive treatment achieved a remission in only $52 \%$ of patients. In case of inhibitor persistence the 1-year mortality increased to $39 \%$ [21, 22]. Compared to these data the depletion of the inhibitor via immunoadsorption allowed an immediate control of the bleeding due to an efficient FVIII recovery (fig. 2).

Our patient collective showed a significant correlation between the inhibitor titer and the time to achieve treatment endpoints, e.g. the days of hospitalization or the consumption of coagulation factors. These results suggest that especially high-titer patients might benefit from the extracorporeal treatment. Additionally the reduction in the FVIII consumption might be another important argument for the apheresis. In the absence of data concerning the amount of factor consumption from other studies, the efficiency of treatment strategies is not comparable [23, 24].

The treatment of bleedings with bypassing factors contrary to FVIII is hampered by the fact that currently no validated laboratory monitoring techniques are available. Therefore, dosages must be adapted to patient's clinical situation, but as mentioned above, a dose escalation is limited by thromboembolic risks [13, 14].

Intensifying the immunosuppressive treatment schedule in $\mathrm{AH}$ was the main strategy to follow by most physicians in the last decade. In this context CD20 B-cell depletion was introduced into the treatment of $\mathrm{AH}[25,26]$.

After an initial enthusiasm, follow-up studies clearly marked that B-cell depletion is not superior to conventional treatments with steroid and cyclophosphamide. In contrast, the observed complete response rate in $\mathrm{EACH} 2$ for rituximab was lower: 41 versus 59\%. There was also no evidence that high-titer patients might benefit from B-cell depletion [24]. In our study, 2 patients failed to respond to rituximab and were treated successfully second line by MBMP.

As mentioned above, relapses after conventional treatment have been reported to occur in $20 \%$ of the patients within a median of 7.5 months [24]. As the 'relapse' event was not further defined, it remains unclear whether the patients experienced bleeding again. In our study the re-occurrence of the inhibitor (low titer) was observed in 4 patients, corresponding to a drop of FVIII concentration to $30-40 \%$ without new bleeding events. 
In 3 patients, an infection anteceded the relapse. All patients had been switched to MBMP as their second line treatment. These data may propose that unsuccessful pretreatments might lead to the development of a more resistant Bcell clone. Nevertheless, in the absence of bleedings these low-titer relapse responded immediately to a short-time treatment as described above.

Complication due to infections is another challenge in the treatment of $\mathrm{AH}$. Interestingly, these incidences are not always associated with neutropenia [4]. Severe hematoma is an important focus for infection and inflammation in AH. On admission most of our patients had a baseline CRP $>60 \mathrm{mg} / \mathrm{dl}$ without further signs of infection, underlining the severity of the inflammatory process in hematomas. Inflammation per se is a potent stimulus for antibody production. Furthermore, a superinfection of hematoma is a serious complication of $\mathrm{AH}$, leading to compartment syndrome. Therefore, a fast regression and degradation of a hematoma is desirable. The substitution with FVIII is more efficient and superior with respect to wound healing and hematoma degradation compared to bypassing factors. Additionally, antibiotic treatment should be initiated generously, and pneumocystis carinii prophylaxis should be taken into consideration depending on the duration of the treatment course of the patient.

In our patient collective, severe neutropenia was seen in only 1 patient. The close monitoring of daily blood cell counts and the dose adaptation of cyclophosphamide to renal function in combination with high-dose steroids prevented severe neutropenia in all other patients.

When compared with the EACH2 Registry data [25], the MBMP achieved a more stable complete remission (93 vs. $70 \%$ ) with a lower relapse rate of 6 versus $18 \%$. Relapses were only seen in patients treated second line with MBMP. The median time to achieve complete response was reached much faster by MBMP when compared with the EACH2 data (16 days vs. 5 weeks). As the MBMP study implemented only patients with severe life-threatening bleedings, a comparison to the data of the EACH2 Registry might be hampered by the fact that the EACH2 Registry makes no differentiation with respect to the severity of $\mathrm{AH}$ and treatment outcome [25].

The data of the EACH2 Registry gives, as well as the implemented studies, no information on the FVIII and bypassing factor consumption. Therefore, a statically based state- ment concerning to the factor-sparing effect of MBMP versus $\mathrm{EACH} 2$ cannot be made. As already shown by our group in 2007 [20], the consumption of factor concentrates decreased considerably after the implementation of immunoadsorption in the treatment of severe AH. Beside the fast bleeding control the reduction of factor concentrate consumption is another main rationale to start apheresis in severe $\mathrm{AH}$ patients.

In our collective of patients, different responses to the treatment between idiopathic AH and AHSAC were not seen [10]. This differentiation was introduced first by Aouba et al. [10], based on their results that idiopathic AH had a 2.3 times higher mortality. As mortality under the MBMP did not occur, it is not possible to calculate different mortalities for AHSAC and idiopathic AH in our study. The intensive shorttime treatment of MBMP might perhaps abolish this handicap and improve patient's prognosis. As $\mathrm{AH}$ is a disorder mainly occurring in elderly persons, malignancy should be considered, especially in patients with a delayed response to treatment [17, 27, 28]. In our collective the malignancy occurred simultaneously with the bleeding disease, suggesting that tumor-specific antigens might induce the immunological reaction. Partial remission was achieved by MBMP, allowing important invasive diagnostic interventions for an exact tumor staging. Definitive inhibitor eradication was only achieved via tumor-adapted treatment.

Therefore, AH with concomitant malignancy should be seen as an own entity of AH underlying in which other than autoimmunological mechanisms may play a role [29]. However, long-term follow-up for a median of 8 years in this rare patient collective confirms the treatment success which is worldwide unique.

In summary, our data confirm the benefit of extracorporeal treatment in $\mathrm{AH}$ management in its acute and therefore also in its long-term outcome. Treatment of AH should be adapted to the patient's clinical situation as in patients with minor bleedings a monotherapy with steroids might be sufficient. In patients with life-threatening bleedings, MBMP should be considered as first line treatment.

\section{Disclosure Statement}

The authors declared no conflict of interest.

\section{References}

1 Hay CR, Brown S, Collins PW, Keeling DM, Liesner R: The diagnosis and management of factor VIII and IX inhibitors: a guideline from the United Kingdom Haemophilia Centre Doctors Organisation. Br J Haematol 2006;133:591-605.

$\checkmark 2$ Mahendra A, Padiolleau-Lefevre S, Kaveri SV, Lacroix-Desmazes S: Do proteolytic antibodies complete the panoply of the autoimmune response in acquired Haemophilia A. Br J Haematol 2011; 156:3-12.
3 Giles AR, Verbruggen B, Roivard GE, Walker I; the Association of Haemophilia Centre of Canada: A detailed comparison of the performance of the standard versus Nijmegen modification of the Bethesda assay in detecting factor VIII: inhibitors in the haemophilia a population of Canada. Thromb Haemost 1998;79:872-875.

4 Collins P: Management of acquired haemophilia A. Thromb Haemost 2011;9(suppl 1):226-235.
5 Zeitler H, Ulrich-Merzenich G, Panek D, Goldmann G, Vidovic N, Brackmann HH Oldenburg J: Immunoadsorption in the treatment of acquired haemophilia. Atherosclerosis Suppl 2009;10:122-125.

6 Gheisari R Bomke B, Hoffman T, Scharf RE: Clinical features and outcome of acquired haemophilia A. Hämostaseologie 2010;30:156-161. 
7 Knoebl P, Marco P, Baudo F, Collins P, HuthKühne A, Nemes L, Pellegrini F, Tengborn L, Lévesque H: Demographic and clinical data in acquired hemophilia a: results from the European Acquired Haemophilia Registry (EACH2). J Thromb Haemost 2012;10:1538-7836.

8 Franchini M: Haemostasis and pregnancy. Thromb Haemost 2006;95:401-413.

9 Collins PW: Treatment of acquired hemophilia. J Thromb Haemost 2007;5:893-900.

10 Aouba A, Rey G, Pavillon G, Jougla E, Rothschild C, Torchet MF, Guillevin L, Hermine O, Aouba A: Deaths associated with acquired haemophilia in France from 2000 to 2009: multiple cause analysis for best care strategies Haemophilia 2012;18:339-344.

-11 Baudo F, Collins P, Huth-Kühne A, Lévesque H, Marco P, Nemes L, Pellegrini F, Tengborn L, Knoebl $\mathrm{P}$; on behalf of the $\mathrm{EACH} 2$ registry contributors: Management of bleeding in acquired hemophilia A :results from the European Acquired Haemophilia (EACH2) Registry. Blood 2012;120:39-46.

12 Delgado J, Yuste V, Navarro F, Villar A: Acquired haemophilia: review and meta-analysis focused on therapy and prognostic factors. Br J Haematol 2003;121:21-35.

13 Ingerslev J, Soorensen B: Parallel use of by-passing agents in haemophilia with inhibitors: a critical review. Br J Haematol 2011;155:256-262.

14 Katgi A, Ataca P, Kahraman S: Ischemic stroke after recombinant factor VIIa treatment in acquired hemophilia A patient. Blood Coag Fibrinolysis 2012;23:69-70.
15 Green D, Lechner K: A Survey of 215 non-haemophilic patients with inhibitors to factor VIII. Thromb Haemost 1981;4:200-203.

16 Girault S, Ly K, Jaccard A, Loustaud V, Turlure P, Julia A, Bordessoule D, Vidal E, Liozon E: Prognosis of acquired hemophilia in older people $\mathrm{J}$ Am Geriatr Soc 2008;56:956-958.

17 Lambotte O, Dautremer J, Guillet B, Boutekedjiret T, Dreyfus M, Kotb R, Le Bras P, Delfraissy JF, Lambert T, Goujard C: Acquired hemophilia in older people: a poor prognosis despite intensive care. J Am Geriatr Soc 2007;55:1682-1685.

18 Zeitler H, Ulrich-Merzenich G, Hess L: Treatment of acquired hemophilia by the Bonn-Malmö Protocol: documentation of an in vivo immunomodulating concept. Blood 2005;105:2287-2293.

19 Zeitler H, Ulrich-Merzenich G, Walger P: Treatment of factor VIII inhibitors with selective IgG immunoadsorption - a single centre experience in 50 patients with acquired hemophilia. Transfus Med Hemother 2006;33:160-164.

20 Zeitler H, Ulrich-Merzenich G, Walger P, Düsing R, Vetter H, Brackmann HH: Das modifizierte Bonn-Malmö Protokoll in der Behandlung der erworbenen Hemmkörperhämophilie - eine multimodale Therapiestrategie. Dtsch Med Wochenschr 2006;131:141-147.

21 Borg J, Levesque H: Epidemiology and one year outcomes in patients with acquired haemophilia (AH) in France: the SACHA prospective study. J Thromb Haemost 2007;5(suppl 2):O-M-062.
$22 \mathrm{Ng} \mathrm{HJ}$, Tan DC, Lee LH: treatment and outcome of acquired haemophilia A with a standard conventional regime in a cohort without associated conditions. Haemophilia 2006;12:423-428.

23 Bitting RL, Bent S, Li Y, Kohlwes J: The prognosis and treatment of acquired hemophilia: a systematic review and meta-analysis. Blood Coagul Fibrinolysis 2009;20:517-523.

24 Collins P, Hirsch S, Baglin TP: Acquired hemophilia in the United Kingdom: a 2 year nationa surveillance study by the United Kingdom Haemophilia Centre Doctors Organisation. Blood 2007; 109:1870-1877.

25 Collins P, Baudo F, Knoebel P et al .Immunosuppression for Acquired hemophilia A: results from the European acquired Haemophilia Registry (EACH2). Blood 2012;120:47-55.

26 Stasi R, Brunetti M, Stipa E, Amadori S: Selective $\mathrm{B}$ cell-depletion with rituximab for the treatment of patients with acquired hemophilia. Blood 2004; 103:4424-4428.

27 Sperr WR, Lechner K, Pabinger I: Rituximab for the treatment of acquired antibodies for factor VIII. Haematologica 2007;92:66-71.

28 Grodreuil S, Navarro R, Qittet L: Acquired haemophilia in the elderly is a severe disease: report of five new cases. Haemophilia 2001;4:428-432.

29 Sallah S, Singh P, Hanrahan LR: Antibodies against factor VIII in patients with solid tumors: successful treatment of cancer may suppress inhibitor formation. Haemostasis 1998;28:244-249. 